\title{
Synthesis and Evaluation of a Water-Swelling Polymer Plugging Agent SWL-1
}

\author{
Li He, Qichao Cao, Xintong Li, Song Wang* \\ School of Chemistry and Environmental Engineering, Yangtze University, Jingzhou, China \\ Email:912801576@qq.com, *150881707@qq.com
}

How to cite this paper: He, L., Cao, Q.C., Li, X.T. and Wang, S. (2021) Synthesis and Evaluation of a Water-Swelling Polymer Plugging Agent SWL-1. Open Journal of Yangtze Gas and Oil, 6, 50-59. https://doi.org/10.4236/ojogas.2021.62005

Received: March 12, 2021

Accepted: April 25, 2021

Published: April 28, 2021

Copyright $\odot 2021$ by author(s) and Scientific Research Publishing Inc. This work is licensed under the Creative Commons Attribution International License (CC BY 4.0).

http://creativecommons.org/licenses/by/4.0/ (c) (i) Open Access

\begin{abstract}
In this paper, to solve the problems of low water absorption and weak pressure bearing capacity of current plugging materials, acrylic acid (AA), acrylamide (AM), and sodium allyl sulfonate (SAS) are used as monomers, and soluble starch is used as grafting. Material, the use of free radical aqueous solution method to synthesize the plugging agent SWL-1 with good water absorption and strong salt resistance. The monomer ratio is set as $\mathrm{n}(\mathrm{AA}): \mathrm{n}(\mathrm{AM}): \mathrm{n}(\mathrm{SAS})=$ 5:2:1, the experimental synthesis temperature is $70^{\circ} \mathrm{C}$, and the orthogonal experiment is used to determine the experimental synthesis conditions as AA neutralization degree $80 \%$, The amount of initiator is $0.60 \%$, the amount of crosslinking agent is $0.50 \%$, the ratio of monomer to starch is $7: 1$, and the amount of calcium carbonate is $13 \%$. The comprehensive evaluation of the performance of the plugging agent SWL-1 shows that the water absorption performance at $60^{\circ} \mathrm{C}$ is the best $268.78 \mathrm{~g} / \mathrm{g}$, and the water absorption performance in $8 \% \mathrm{NaCl}, 0.9 \% \mathrm{CaCl}_{2}$ and composite brine is $21.5 \mathrm{~g} / \mathrm{g}, 12.5 \mathrm{~g} / \mathrm{g}$ and $24.9 \mathrm{~g} / \mathrm{g}$, indicating good resistance to sodium and calcium, the water retention rate is still higher than $30 \%$ after 15 days at $160^{\circ} \mathrm{C}$. The sand bed plugging test found that the maximum pressure of SWL-1 was $7 \mathrm{MPa}$, and the crack plugging test found that when the crack width was $1 \mathrm{~mm}, 2 \mathrm{~mm}$, and 3 $\mathrm{mm}$, the maximum compressive strength of SWL-1 was $10 \mathrm{MPa}$. The acid solubility test showed that the maximum pressure was $10 \mathrm{MPa}$. The highest rate is $86.38 \%$.
\end{abstract}

\section{Keywords}

Plugging Agent, Water Absorption, Sand Bed Plugging, Crack Plugging, Acid Solubility

\section{Introduction}

Lost circulation is one of the most common and common complex problems 
encountered in the process of petroleum development. It is usually caused by the penetration of drilling fluids, completion fluids, workover fluids and other working fluids into the formation, which damages the oil layer [1] [2] [3] [4] [5]. Loss damage to the oil layer is not only reflected in the damage to the oil layer and the decline in oil production, but also the prolonged drilling cycle, the loss of drilling fluid, completion fluid and other working fluids, loss of plugging materials, interference with geological logging, etc. It will cause well collapse, sticking, and in severe cases, the wellbore will be scrapped [6] [7] [8] [9] [10]. Although there have been many researches on plugging agents at home and abroad, most of them are about gel material plugging, bridging material plugging, cement material plugging, etc., or starch grafting expansion polymer plugging. There are few reports of leakage. The main reasons are: one is that the expansion capacity of the swellable plugging agent is uncontrollable; the other is that the plugging agent expands before it enters the missing position, which makes it impossible to enter the missing position for plugging. The third is plugging. The strength of the agent is not enough [11]-[16]. Therefore, a water-swelling plugging material SWL-1 was prepared indoors, and its performance was evaluated.

\section{Experimental Part}

\subsection{Experimental Drugs and Instruments}

1) Main experimental drugs: sodium hydroxide, acrylic acid (AA), acrylamide (AM), sodium allyl sulfonate (SAS), Crosslinking agent ( $\mathrm{N}-\mathrm{N}$ methylene bisacrylamide), soluble starch, initiator, superfine calcium carbonate.

2) Main experimental instruments: DHG type electric heating constant temperature blast drying oven, DF-101Z heat collecting magnetic stirrer, high temperature heat roller furnace, multi-function grinder, Soxhlet extractor, high temperature and high pressure sand bed filter loss instrument, QD-2 type plugging material experimental device.

\subsection{Orthogonal Optimization of Experimental Conditions}

Since the plugging agent is produced by the reaction of soluble starch, monomers, cross-linking agents, initiators and other substances, the development of the plugging agent requires many factors to consider [17] [18] [19] [20], and the monomer ratio is set as $\mathrm{n}(\mathrm{AA}): \mathrm{n}(\mathrm{AM}): \mathrm{n}(\mathrm{SAS})=5: 2: 1$, the experimental synthesis temperature is $70^{\circ} \mathrm{C}$, the dosage of initiator, monomer starch ratio, crosslinker and neutralization degree of AA were changed, the orthogonal experiment of the experiment is set to $L 9\left(3^{4}\right)$, to find an optimal experimental condition, Get the best performance plugging agent. Table 1 shows the level of orthogonal experiment factors, Table 2 shows the orthogonal experimental results, and Table 3 shows the analysis of the orthogonal experimental results.

According to the results and analysis of orthogonal experiments, the best synthetic conditions for plugging agent SWL-1 are AA neutralization degree $80 \%$, initiator addition amount $0.60 \%$, crosslinking agent addition amount 
$0.50 \%$, monomer starch ratio 7:1. The order of influencing factors on swl-1 is AA neutralization degree, initiator dosage, crosslinker dosage and monomer starch ratio.

Table 1. Orthogonal experiment factor level.

\begin{tabular}{ccccc}
\hline Level & $\begin{array}{c}\mathrm{A} \\
\text { Initiator } \\
(\%)\end{array}$ & $\begin{array}{c}\mathrm{B} \\
\text { Monomer } \\
\text { starch ratio (\%) }\end{array}$ & $\begin{array}{c}\mathrm{C} \\
\text { Crosslinking } \\
\text { agent (\%) }\end{array}$ & $\begin{array}{c}\mathrm{D} \\
\text { AA neutralization } \\
\text { degree (\%) }\end{array}$ \\
\hline 1 & 0.50 & $6: 1$ & 0.30 & 75 \\
2 & 0.60 & $7: 1$ & 0.50 & 80 \\
3 & 0.70 & $8: 1$ & 0.70 & 85 \\
\hline
\end{tabular}

Table 2. Orthogonal experiment results.

\begin{tabular}{cccccc}
\hline \multirow{2}{*}{ test serial number } & \multicolumn{5}{c}{ factor } \\
\cline { 2 - 5 } & A & B & C & D & Absorbent multiples (g/g) \\
\hline 1 & 1 & 1 & 1 & 1 & 232.32 \\
2 & 1 & 2 & 2 & 2 & 168.34 \\
3 & 1 & 3 & 3 & 3 & 208.35 \\
4 & 2 & 1 & 2 & 3 & 198.36 \\
5 & 2 & 2 & 3 & 1 & 212.31 \\
6 & 2 & 3 & 1 & 2 & 190.36 \\
7 & 3 & 1 & 3 & 2 & 160.89 \\
8 & 3 & 2 & 1 & 3 & 140.68 \\
9 & 3 & 3 & 2 & 1 & \\
\hline
\end{tabular}

Table 3. Analysis of orthogonal experiment results.

\begin{tabular}{crrrc}
\hline factor & $\mathrm{A}$ & $\mathrm{B}$ & $\mathrm{C}$ & $\mathrm{D}$ \\
\hline $\mathrm{k} 1$ & 164.93 & 164.34 & 155.84 & 144.45 \\
$\mathrm{k} 2$ & 206.34 & 197.12 & 193.72 & 211.60 \\
$\mathrm{k} 3$ & 163.98 & 173.68 & 185.68 & 179.19 \\
extremum R & 42.36 & 32.78 & 37.88 & 67.15 \\
\hline
\end{tabular}

\subsection{Preparation of Plugging Agent}

Weigh $3 \mathrm{~g}$ of soluble starch into the flask, then add $120 \mathrm{~mL}$ of distilled water, heat at $85^{\circ} \mathrm{C}$ for half an hour, and pass nitrogen protection. After the starch is fully gelatinized, stop heating, and wait until the gelatinized starch is cooled to $60^{\circ} \mathrm{C}$. Weigh an appropriate amount of superfine calcium carbonate and dissolve it in water to prepare an emulsion and add it to it. Adjust the neutralization degree of acrylic acid to $80 \%$ with $40 \% \mathrm{NaOH}$, then add the monomers, initiators, and crosslinkers in sequence, and place them on a magnetic stirrer with a set temperature $\left(70^{\circ} \mathrm{C}\right)$ and heat for 3 hours. The obtained product is mixed with 
acetone, purified by a Soxhlet extractor, washed with absolute ethanol several times, placed in an oven with a set temperature for drying, crushed and sieved to obtain the product.

The strength of the plugging agent obtained by grafting monomers acrylic acid (AA), acrylamide (AM), and sodium allyl sulfonate (SAS) through starch is lower. Adding more monomers can increase the strength of the plugging agent, but it will also increase the cost. Adding a small amount of inorganic materials to the plugging agent can not only improve the strength of the plugging agent, but also will not increase too much cost. Calcium carbonate plays a very good filling and supporting role in the space structure of the plugging agent. It can not only improve the pressure resistance of the plugging agent, but also will not cause the problem of difficult glue breaking in the later stage. Based on the above optimal synthesis conditions, superfine calcium carbonate of different proportions was added during the experiment to test the water absorption performance and salt resistance under different dosages.

It can be seen from Table 4 that calcium carbonate has a greater impact on the water absorption performance of the plugging agent SWL-1, but has a small impact on the salt resistance. With the increase of calcium carbonate, the water absorption performance of the plugging agent SWL-1 increases. When calcium carbonate is added at $13 \%$, SWL-1 has the best water absorption performance and good salt resistance. Continuing to increase the amount of calcium carbonate added result in a decrease in the proportion of monomers, resulting in a decrease in the water absorption performance of SWL-1.

Table 4. The effect of calcium carbonate addition on the performance of the plugging agent.

\begin{tabular}{ccc}
\hline $\mathrm{CaCO}_{3}$ addition $(\%)$ & Water absorption performance $(\mathrm{g} / \mathrm{g})$ & Salt resistance $(\mathrm{g} / \mathrm{g})$ \\
\hline 4 & 106.41 & 26.46 \\
7 & 151.31 & 24.89 \\
10 & 219.85 & 29.36 \\
13 & 251.37 & 25.37 \\
16 & 238.66 & 24.90 \\
19 & 218.48 & 26.09 \\
\hline
\end{tabular}

Note: The proportion of brine is water $+4 \% \mathrm{NaCl}+0.5 \% \mathrm{CaCl}_{2}+1.3 \% \mathrm{MgCl}_{2}$.

\section{Performance Evaluation}

\subsection{Evaluation of Water Absorption Performance}

Weigh a number of $5 \mathrm{~g}$ plugging agent SWL-1, put them in the aging tank, add $400 \mathrm{~mL}$ of water, place them at different temperatures and roll them, take them out at regular intervals, and then filter out the unabsorbed water. The SWL-1 after absorbing water after standing for a period of time, the polymer mass $m_{2}$ after water absorption was weighed several times, until the mass of the plugging agent SWL-1 remained unchanged [21]. The water absorption multiple $Q$ of the 
plugging agent is expressed by the formula:

$$
Q=\left(m_{2}-m_{1}\right) / m_{1}
$$

Among them, $m_{1}$ is the mass of the plugging agent before water absorption, and $m_{2}$ is the mass of the plugging agent at a certain time at a certain temperature after water absorption.

Test the water absorption performance of SWL-1 at room temperature of $20^{\circ} \mathrm{C}, 60^{\circ} \mathrm{C}, 100^{\circ} \mathrm{C}, 140^{\circ} \mathrm{C}$, and $160^{\circ} \mathrm{C}$. From Table 5, it can be seen that SWL-1 has the best water absorption performance at $60^{\circ} \mathrm{C}$, and the water absorption capacity at $120 \mathrm{~min}$. It is close to saturation. As the temperature increases, the water absorption performance decreases to a certain extent. It may be due to the increase in temperature that the extensibility of SWL-1 in water is weakened to a certain extent, resulting in the high temperature of SWL-1. The water absorption capacity is reduced.

Table 5. Water absorption performance of resin at different temperatures.

\begin{tabular}{cccccc}
\hline Absorbent multiples (g/g) & $20^{\circ} \mathrm{C}$ & $60^{\circ} \mathrm{C}$ & $100^{\circ} \mathrm{C}$ & $140^{\circ} \mathrm{C}$ & $160^{\circ} \mathrm{C}$ \\
\hline $30 \mathrm{~min}$ & 63.78 & 106.78 & 80.82 & 71.21 & 65.43 \\
$60 \mathrm{~min}$ & 103.23 & 160.67 & 140.26 & 120.93 & 80.68 \\
$90 \mathrm{~min}$ & 180.67 & 247.32 & 190.73 & 157.82 & 90.34 \\
$120 \mathrm{~min}$ & 230.45 & 268.78 & 210.39 & 170.98 & 100.89 \\
$150 \mathrm{~min}$ & 230.45 & 268.78 & 210.39 & 170.98 & 100.89 \\
\hline
\end{tabular}

\subsection{Salt Resistance}

Prepare $2.0 \% \mathrm{NaCl}$ salt solution, $4.0 \% \mathrm{NaCl}$ salt solution, $6.0 \% \mathrm{NaCl}$ salt solution, $8.0 \% \mathrm{NaCl}$ salt solution, $0.3 \% \mathrm{CaCl}_{2}$ salt solution, $0.5 \% \mathrm{CaCl}_{2}$ salt solution, $0.7 \% \mathrm{CaCl}_{2}$ saline solution, $0.9 \% \mathrm{CaCl}_{2}$ saline solution, composite brine (4\% $\mathrm{NaCl}+0.5 \% \mathrm{CaCl}_{2}+1.3 \% \mathrm{MgCl}_{2}$ ), accurately weigh a number of unit mass samples and place them in the prepared salt solution for salt resistance test.

From Figure 1, it is found that the water absorption effect of the resin plugging agent in $\mathrm{NaCl}$ brine is better than that in $\mathrm{CaCl}_{2}$ brine, indicating that the anti-Na ${ }^{+}$ability of SWL-1 is better than the anti-Ca ${ }^{2+}$ ability, and at the same time, with the concentration of $\mathrm{NaCl}$ and $\mathrm{CaCl}_{2}$ salt solutions with the increase of, the water absorption performance of SWL-1 has declined to a certain extent, but it can still show good water absorption performance. The water absorption performance in composite brine is between $\mathrm{NaCl}$ brine and $\mathrm{CaCl}_{2}$ brine, and has good salt resistance. From the figure, it is found that SWL-1 performs well in the first 30 hours, and after 30 hours, it tends to be saturated.

\subsection{Water Retention Performance at Different Temperatures}

Weigh several parts of the plugging agent per unit mass, add them to a beaker with sufficient water, take out after fully absorbing the water, and then filter out the excess water. After standing for a while, weigh the mass of the plugging agent 


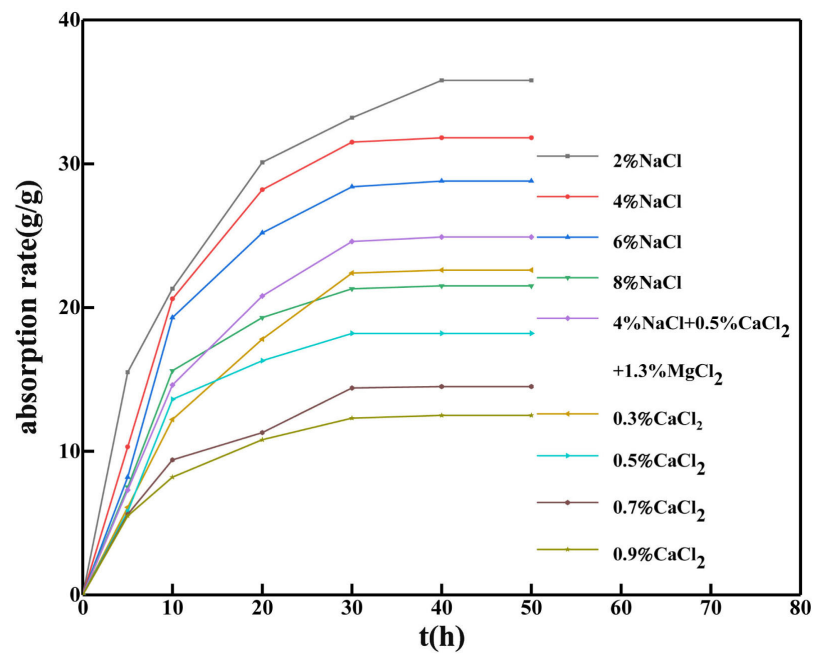

Figure 1. Salt resistance of resin under different salt concentrations.

several times and place them separately. Under the conditions of $20^{\circ} \mathrm{C}, 60^{\circ} \mathrm{C}$, $100^{\circ} \mathrm{C}, 140^{\circ} \mathrm{C}$, and $160^{\circ} \mathrm{C}$, filter and weigh the mass $\mathrm{mt}$ of the plugging agent at regular intervals. The water retention rate $\mathrm{WR}$ of the plugging agent is expressed by the formula:

$$
\mathrm{WR}=\left(m_{\mathrm{t}} / m_{1}\right) * 100 \%
$$

Among them, $m_{1}$ is the mass of the plugging agent after absorbing water; $m_{\mathrm{t}}$ is the mass of the plugging agent at time $t$.

Experiments have tested the water retention capacity of the resin at $20^{\circ} \mathrm{C}$, $60^{\circ} \mathrm{C}, 1000^{\circ} \mathrm{C}, 140^{\circ} \mathrm{C}$, and $160^{\circ} \mathrm{C}$. From Figure 2, at low temperatures, temperature has little effect on the water retention performance of the resin. As the temperature rises, the water retention capacity of the resin the capacity has declined, but the water retention rate of SWL-1 can still be maintained above $10 \%$ after more than 20 days at high temperature, showing good water retention performance and temperature resistance.

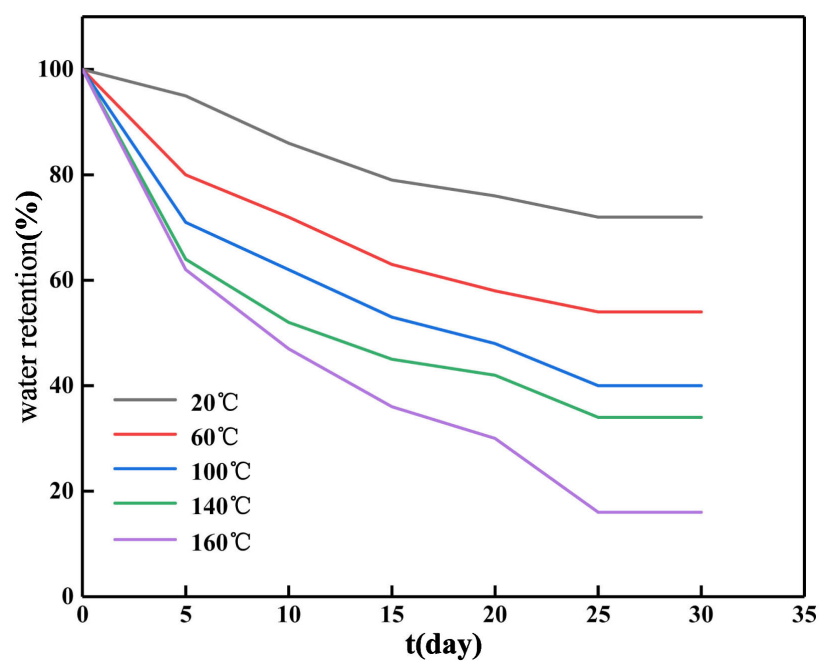

Figure 2. Water retention properties of resins at different temperatures. 


\subsection{Plugging Performance}

According to the "Experimental Test Method of Bridging Plugging Material for Drilling" (SY/T5840-2007) [22], the QD-2 type plugging material experimental device is used to test the plugging ability of the plugging agent. The drilling fluid formula used for plugging is distilled water $+5 \%$ sodium bentonite, and then $3 \%, 4 \%$, and $5 \%$ SWL- 1 are added to perform sand bed plugging test.

It can be seen from Table 6 that SWL-1 has a good plugging effect in the sand bed, and its pressure-bearing capacity is greater than $6 \mathrm{MPa}$. Comparing GWS-1 [23] and KP [24], SWL-1 has a good pressure-bearing strength or in terms of total leakage, it has obvious advantages.

Table 6. Loss of plugging agent in sand bed.

\begin{tabular}{ccc}
\hline Plugging fluid formula & Compressive strength/MPa & Total loss $/ \mathrm{mL}$ \\
\hline Base slurry + 4\% SWL-1 & 6 & 34 \\
Base slurry + 4\% KP & 3 & 114 \\
Base slurry + 4\% GWS-1 & 3 & 130 \\
Base slurry + 5\% SWL-1 & 7 & 42 \\
Base slurry + 5\% KP & 4 & Press through within 1 min \\
Base slurry $+5 \%$ GWS-1 & 3 & 154 \\
\hline
\end{tabular}

Note: The quartz sand of $0.5-2.0 \mathrm{~mm}$ is used in the experiment.

It can be seen from Table 7 that the plugging agent has a good plugging ability for cracks of 1 to $3 \mathrm{~mm}$. In the case of different dosages, the pressure bearing capacity is greater than $6 \mathrm{MPa}$, and the highest can reach $10 \mathrm{MPa}$. Comparing GWS-1 and KP, SWL-1 has high compressive strength and small leakage in 1 - 3 $\mathrm{mm}$ crack plugging, and it can plug the cracks well.

Table 7. Plugging effect of plugging agent in different fractures.

\begin{tabular}{cccc}
\hline Plugging fluid formula & Crack width/mm & Compressive strength/MPa & Total loss/mL \\
\hline Base slurry + 3\% GWS-1 & $1 / 2 / 3$ & $2 / 1 / 0.69$ & $80 / 170 / 320$ \\
Base slurry + 3\% SWL-1 & $1 / 2 / 3$ & $8.6 / 7.2 / 6$ & $16 / 24 / 32$ \\
Base slurry + 3\% KP & $1 / 2 / 3$ & $4 / 3 / 2.3$ & $100 / 130 / 246$ \\
Base slurry + 5\% GWS-1 & $1 / 2 / 3$ & $3 / 2 / 1.5$ & $16 / 45 / 160$ \\
Base slurry + 5\% SWL-1 & $1 / 2 / 3$ & $10 / 8.2 / 6.5$ & $12 / 20 / 26$ \\
Base slurry + 5\% KP & $1 / 2 / 3$ & $4.6 / 3.5 / 2.8$ & $78 / 98 / 123$ \\
\hline
\end{tabular}

\subsection{Acid Solubility}

Not only is it required that the plugging agent SWL-1 has a good pressure bearing capacity, but it must also be required not to affect the later removal of the plugging. In the experiment, SWL-1 with a calcium carbonate addition amount of $13 \%$ was selected, and dilute hydrochloric acid with a concentration of $36 \%$ was used to prepare a hydrochloric acid solution with a $\mathrm{pH}$ of 1 to 7 , and a cer- 
tain amount of plugging agent SWL-1 was added at $3 \mathrm{~h}, 6 \mathrm{~h}$, and $6 \mathrm{~h}$ respectively. $9 \mathrm{~h}$ filter and weigh.

It can be seen from Table 8 that the plugging agent SWL-1 dissolves very well in acid, with a maximum of $86.38 \%$. Under acidic conditions, with the decrease of $\mathrm{pH}$, the acid solubility of SWL-1 increases, which does not affect the later removal of plugging.

Table 8. Acid soluble effect of plugging agent under different $\mathrm{pH}$ values.

\begin{tabular}{cccc}
\hline $\mathrm{pH}$ value & $2 \mathrm{~h}$ dissolution rate/\% & 4 h dissolution rate/\% & 8 h dissolution rate/\% \\
\hline 1 & 84.48 & 86.37 & 86.38 \\
2 & 80.39 & 81.21 & 81.21 \\
3 & 31.26 & 34.87 & 34.89 \\
4 & 15.37 & 21.86 & 21.86 \\
5 & 1.34 & 9.05 & 9.05 \\
6 & 0.02 & 8.31 & 8.32 \\
7 & 0 & 0 & 0 \\
\hline
\end{tabular}

\section{Conclusions}

1) Using orthogonal experiment to determine the optimal conditions for the experiment are AA neutralization degree $80 \%$, initiator addition amount $0.60 \%$, crosslinking agent addition amount $0.50 \%$, monomer starch ratio $7: 1$, calcium carbonate addition amount $13 \%$.

2) Test the water absorption, salt resistance, water retention, plugging test and acid dissolution test of the plugging agent SWL-1. The best water absorption performance is $268.78 \mathrm{~g} / \mathrm{g}$ at $60^{\circ} \mathrm{C}$, in $8 \% \mathrm{NaCl}$, the water absorption properties of $0.9 \% \mathrm{CaCl}_{2}$ and composite brine are $21.5 \mathrm{~g} / \mathrm{g}, 12.5 \mathrm{~g} / \mathrm{g}$ and 24.9 $\mathrm{g} / \mathrm{g}$, respectively. The water retention rate is still greater than $30 \%$ after 15 days at a high temperature of $160^{\circ} \mathrm{C}$, showing good water retention and resistance temperature. The sand bed can be under pressure of $7 \mathrm{MPa}$ in the plugging test, and the sealing plate plugging experiment can plug the cracks of 1 to $3 \mathrm{~mm}$. The effect is very good, and the pressure strength is $8 \mathrm{MPa}$, and the acid solubility rate can reach $86.38 \%$, which does not affect the later removal of the plugging.

\section{Funding}

National Natural Science Foundation of China "Research on Fundamental Theory of Shale Oil and Gas Efficient Development" (No. 51490650).

\section{Conflicts of Interest}

The authors declare no conflicts of interest regarding the publication of this paper. 


\section{References}

[1] Eric, D., Lee, R. and Simon, Z. (2000) Control of Lost Circulation in Fractured Limestone Reservoirs. The IADC/SPE Asia Pacific Drilling Technology, Kuala Lumpur, September 2000, 1-9. https://doi.org/10.2118/62734-MS

[2] Ge, Q.Y. (2017) Development of a New Type of Gel Plugging Agent and Its Application in Workover Fluid. China University of Petroleum, Beijing.

[3] Mahmoud, E., Ahmad, E., Moataz, A., et al. (2007) Successes in Curing Massive Lost-Circulation Problems with a New Expansive LCM. The SPE/IADC Middle East Drilling and Technology Conference, Cairo, October 2007, 1-5. https://doi.org/10.2118/108290-MS

[4] Deng, Z.Q., Jiang, G.C., Yang, L.L., et al. (2018) Microencapsulation of 2,2'-Azobis(2methylpropionamide) Dihydrochloride Initiator Using Acrylonitrile Butadiene Styrene as Shell for Application in Lost-Circulation Control. Colloids \& Surfaces A: Physicochemical \& Engineering Aspects, 553, 134-142. https://doi.org/10.1016/j.colsurfa.2018.05.016

[5] Hu, J. (2020) Preparation and Performance Study of Graft-Modified Polyacrylic Acid Super Absorbent Resin. Hefei University of Technology, Hefei.

[6] Zhang, N. (2020) Preparation and Performance Study of Starch Grafting/Binary Copolymerization Modified Polyacrylic Acid-Based Super Absorbent Resin. Hefei University of Technology, Hefei.

[7] Zhang, J.Q. (2018) Development of Starch-Based Degradable Temporary Plugging Agent and Its Application in Drilling Fluid. China University of Petroleum (East China), Beijing.

[8] Li, Y. (2018) Research and Application of Starch Grafted Copolyacrylamide Polymer Gel System. China University of Geosciences, Beijing.

[9] Jiang, X.Q., Guan, R.C., Hao, J.S., et al. (2020) Development of a Reactive Gel Plugging Agent. Advances in Fine Petrochemicals, 21, 1-5.

[10] Zhang, Q., Xu, X.G., Dong, W., et al. (2006) Research and Application of Delayed Expansion Granular Plugging Agent. Drilling Fluids and Completion Fluids, No. 2, 21-24+85.

[11] Yan, B.C., Jiang, G.C., Hu, W.J., et al. (2019) Study on High Temperature Delayed Crosslinking Polyacrylamide Gel Plugging Agent. Drilling Fluids and Completion Fluids, 36, 679-682.

[12] Ying, C.Y., Gao, Y.H., Duan, L.C., et al. (2017) Development and Evaluation of a New Type of Water-Absorbing Swelling Plugging Agent. Drilling Fluids and Completion Fluids, 34, 38-44.

[13] Wang, H.J. (2017) Development of Water-Absorbing Swellable Resin Plugging Material and Its Indoor Performance Evaluation. Energy Chemical Industry, 38, 68-72.

[14] Ma, F.J. (2015) Water-Absorbent Resin Plugging Agent and Its Mechanism of Action. Southwest Petroleum University, Chengdu.

[15] Xia, H.Y., Zhou, S., Lan, L., et al. (2011) Development and Performance Evaluation New Method of GCY-X Body Swelling Plugging Agent. Drilling Fluids and Completion Fluids, 28, 11-13+91-92.

[16] Li, B.R. (2015) Development of Composite Ionic Polymer Gel Plugging Agent. Northeast Petroleum University, Daqing.

[17] Di, L.L. (2007) Research on Plugging Technology of Super Absorbent Resin. Southwest Petroleum University, Chengdu.

[18] Jia, J., Guo, J.H., Zhao, X.H., et al. (2012) Performance Evaluation and Research of 
Water-Absorbing Swellable Plugging Materials. Drilling and Completion Fluids, 29, $16-19+23+88$.

[19] Tang, D.X., Liu, Z.D., Hou, Y.G., et al. (2008) Development of Controllable Expansion Plugging Agent. Drilling Fluids and Completion Fluids, No. 5, 20-22+84.

[20] Yu, C. (2016) Research on Polymer Gel Plugging Technology. China University of Geosciences, Beijing.

[21] Li, J., Liu, W.T., Liu, X.Y., et al. (2012) Performance Evaluation of High-Strength Salt-Resistant Water-Absorbent Resin for Leak Plugging. Drilling Fluids and Completion Fluids, 29, 13-15+96.

[22] SY/T 5840-2007, Laboratory Test Method of Bridging and Plugging Materials for Drilling Fluid.

[23] Huang, C.Y., Ouyang, W., Liu, X.J., et al. (2014) Indoor Performance Study of Cross-Linked Polymer Plugging Agent. Petrochemical Industry Application, 33, 93-97.

[24] Miao, J. (2010) Development and Performance Study of Controllable Expansion Plugging Agent. Southwest Petroleum University, Chengdu. 